\title{
POBREZA NO BRASIL E NA METRÓPOLE DO RIO DE JANEIRO: velhos problemas, novos dilemas
}

\author{
Marcelo Gomes Ribeiro* \\ Felipe Camargo Raitano**
}

\begin{abstract}
O presente artigo tem o objetivo de analisar quantitativamente a trajetória da pobreza no Brasil e na metrópole do Rio de Janeiro, considerando o período de 1976 a 2015, tendo em vista as mudanças estruturais ocorridas na economia e na sociedade brasileira e as particularidades do contexto metropolitano. A linha de pobreza utilizada foi definida segundo o dobro do nível de renda suficiente para a aquisição de uma cesta de alimentos necessária para garantir a reprodução cotidiana do indivíduo. Pudemos observar que a taxa de pobreza variou de acordo com a conjuntura econômica com diferenças de níveis e de intensidade entre a metrópole e o país. Atualmente, as pessoas em situação de pobreza, ao contrário de décadas atrás, em geral, estão mais jovens/adultas, possuem níveis de instrução mais elevados e exercem ocupações que representam posições sociais mais destacadas na estrutura social, o que pode ter implicações importantes nas mudanças de expectativas de superação dessa condição, em especial no contexto metropolitano.

PALAVRAS-ChavE: Pobreza. Metrópole do Rio de Janeiro. Brasil. Desenvolvimento Econômico. Estrutura Econômica.
\end{abstract}

\section{INTRODUÇÃO}

O Brasil se tornou um país rico, mas com parcela expressiva de sua população pobre. Por muitas décadas, essa foi considerada uma das suas grandes marcas, a ponto de não ser reconhecido até hoje como um país desenvolvido, tendo em vista que a condição de desenvolvimento passou a considerar a conjunção entre crescimento econômico e as condições de vida da população. Apesar das oscilações para cima e para baixo do nível de pobreza ao longo dos anos, o quantitativo de pobres sempre foi elevado, colocando-se como uma das questões mais prementes para a sociedade brasileira. De meados da primeira década do século XXI até o começo da década seguinte, todavia, tudo in-

* Universidade Federal do Rio de Janeiro. Instituto de Pesquisa e Planejamento Urbano e Regional (IPPUR/UFRJ)

Avenida Athos da Silveira Ramos, 149 - Nicho 2, bloco I2000 - Prédio Centro de Tecnologia - CT Ilha do Fundão, Cidade Universitária. Cep: 21.941-909. Rio de Janeiro Rio de Janeiro - Brasil. marceloribeiro@ippur.ufrj.br https://orcid.org/0000-0001-7448-0690

** Universidade Federal do Rio de Janeiro. Instituto de Pesquisa e Planejamento Urbano e Regional (IPPUR/UFRJ) Avenida Athos da Silveira Ramos, 149 - Nicho 2, bloco I2000 - Prédio Centro de Tecnologia - CT Ilha do Fundão, Cidade Universitária. Cep: 21.941-909. Rio de Janeiro Rio de Janeiro - Brasil. felipe.raitano@gmail.com https://orcid.org/0000-0003-0260-4898 dicava que o país poderia, enfim, galgar o patamar das nações mais desenvolvidas, pois a pobreza passou a ser reduzida de modo sistemático, atingindo níveis nunca observados em sua trajetória. A partir de 2015, porém, o nível de redução da pobreza no Brasil passou a dar sinais de retrocesso.

Refletir sobre o significado da pobreza na atualidade, tendo em vista o retorno do seu crescimento, mostra-se fundamental na medida em que aqueles que se encontram nessa condição (e aqueles que estão se tornando pobres) estão vivendo essa experiência após um período contínuo de melhorias que prometiam mitigar a pobreza. Além disto, a experiência da pobreza de quem sempre foi pobre pode ser muito diferente da experiência daqueles que passaram a viver essa condição; e a experiência da pobreza após um período em que sua trajetória mostrava sinais de declínio, frustra expectativas individuais e coletivas com o futuro da sociedade.

O momento atual, em certa medida, apresenta paralelos com os anos 1980, pois, tanto naquela época quanto agora, o país se encontrava em situação de crise econômica, re- 
gistrado pelo baixo nível do PIB, ${ }^{1}$ e crise social, observada, entre outras coisas, pela redução do poder de compra. Embora os motivos da crise naquele período sejam muito diferentes dos causadores da crise atual, tanto lá quanto cá, a crise econômica e social foi precedida por um período robusto de crescimento econômico, mais robusto naquele período do que neste. $\mathrm{Na}$ verdade, nesses 30 anos que separam um período do outro, houve mudanças significativas na sociedade brasileira que precisam ser compreendidas para se entender a dimensão do significado da pobreza na atualidade. Algumas dessas mudanças tiveram caráter estrutural, tendo em vista que colocou a sociedade em outro patamar quando comparados os dois momentos. Outras mudanças são observadas em cada conjuntura, mas deve-se ter em mente aquelas de caráter estrutural.

Entre estas, uma que não pode ser negligenciada é o fato de a sociedade brasileira ser muito mais urbana do que era naquele período. Portanto, para entender a pobreza na atualidade é necessário compreender que a maioria daqueles que se encontram nessa condição está experimentando a pobreza nas cidades e, em grande medida, nas grandes cidades. Por esse motivo, vamos focar nossa análise sobre a pobreza existente na metrópole do Rio de Janeiro. Por ser uma das principais metrópoles do país, onde a experiência urbana se expressa em toda sua inteireza, coloca-se como um caso จิ particular do possível (Bourdieu, 2003), no s sentido de que a análise dessa experiência concreta pode revelar questões que dizem respeito à problemática da pobreza de modo universal, $\stackrel{\infty}{\rightarrow}$ pelo menos para a realidade urbana do Brasil.

Este trabalho está estruturado em mais 今 sete seções, além desta introdução. Na segun-

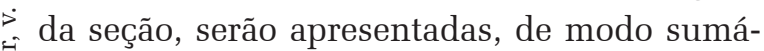
rio, as diversas abordagens sobre pobreza e a justificativa da abordagem que será aqui utili-

${ }^{1}$ Para isto, toma-se como referencia a taxa média de crescimento do PIB, que no período de 1971 a 1980 foi de 8,7\% a.a; no período de 1981 a 1990 foi de 1,7\% a.a; e de 1991 a 2000 foi de 2,6\% a.a. De 2001 a 2010 foi de 3,7\% a.a. e de 2011 a 2019 foi de $0,8 \%$ a.a. zada. Na terceira seção, será apresentada a trajetória da pobreza no Brasil e na metrópole do Rio de Janeiro, no período de 1976 a 2015. Na quarta seção, serão discutidos vários aspectos das mudanças estruturais ocorridas no Brasil desde os anos 1970 até os dias atuais, tentando apresentar as diferentes conjunturas inseridas nessa estrutura. Na quinta seção, buscaremos apresentar algumas das particularidades da metrópole do Rio de Janeiro em relação ao contexto nacional. Na sexta seção, serão apresentadas algumas características das pessoas em situação de pobreza de modo a refletir sobre as mudanças de seu perfil ao longo das últimas três décadas. Na sétima seção, buscaremos discutir o sentido da pobreza na atualidade a partir da reflexão ao longo deste trabalho. E nas considerações finais, serão sumarizadas as principais reflexões realizadas aqui.

\section{AS DIVERSAS ABORDAGENS SO- BRE POBREZA}

A Revolução Industrial alterou as formas de pensar e agir em relação à pobreza. Devemos ressaltar diferentes abordagens que caracterizaram esse fenômeno, principalmente durante os séculos XX e XXI, nos quais as transformações ocorridas na sociedade levaram a mudanças no entendimento desse fenômeno, que partiam de uma noção unidimensional e pautada apenas na renda, para uma análise multidimensional, priorizando outros aspectos além da renda (Codes, 2008). Essas abordagens podem ser denominadas como: subsistência, necessidades básicas, privação relativa, privação das capacidades e multidimensional, como serão apresentadas em seguida.

A primeira abordagem, conhecida como da subsistência, foi constituída na Inglaterra no fim do século XIX e pode ser dividida em duas grandes fases. Na primeira, define-se os pobres como aqueles que não possuem renda suficiente para alcançar o nível de alimentação que permite sua reprodução física. Destaca-se aqui o forte papel das instituições civis que 
atuavam para atenuar a questão da pobreza. Na segunda, que ocorreu nos anos posteriores à Segunda Guerra Mundial, a pobreza passa a ser entendida como um obstáculo à manutenção da coesão social e, torna-se, assim, alvo de políticas públicas de Estado. Para isso, as ações estatais se concentraram na manutenção do pleno emprego como forma de possibilitar o acesso à alimentação, resultando em uma maior segurança social para os cidadãos ingleses. A renda surge como peça fundamental nessa abordagem, pois, através dela, seria possível acessar esses recursos.

A segunda, a abordagem das necessidades básicas, entende que a satisfação destas pode ser benéfica para o crescimento econômico e, dessa forma, contribuir com o progresso social. A pobreza, nesse caso, ganha uma visão multifacetada, além da renda, incluindo-se nela o padrão mínimo de vida do indivíduo (comida, moradia, roupas etc.) e da comunidade (acesso à água potável, transporte, saúde e educação) (Rocha, 2003). Quando se estuda a pobreza a partir da variável renda é comum categorizar grupos a partir de linhas de pobreza e extrema pobreza. Assim, a linha de pobreza estabelece um nível de renda suficiente para a obtenção de um conjunto mais amplo de necessidades que garantam a reprodução social do indivíduo. Já a linha de extrema pobreza trata especificamente das necessidades nutricionais que garantam a reprodução física das pessoas, categorizando-se os indivíduos a partir de seu nível de renda e do valor das referidas linhas. Nota-se que esta utilização representa uma interação entre as abordagens da subsistência e das necessidades básicas.

A terceira abordagem, da privação relativa, passa a dar pesos particulares a cada um dos indicadores analisados conforme sua valorização pela sociedade em que estão inseridos e para os indivíduos que dela fazem parte. A noção de privação relativa passa a se afastar da ideia de indicadores e pesos universais que possam retratar a pobreza. Nessa perspectiva, a pobreza é definida em função do contexto social em que se vive, a partir da consideração de um padrão de vida especifico e da maneira como as diferentes necessidades são supridas em uma dada realidade socioeconômica.

Já a abordagem da privação das capacidades avança no sentido de ampliar, aprofundar e incorporar outras dimensões na conceituação sobre o que é pobreza (Bagolin; Ávila, 2006). Dá-se maior ênfase ao campo da justiça social, discutindo aspectos de desenvolvimento, bem-estar, liberdade, igualdade, desigualdade, tendo como núcleo a noção da capacidade dos indivíduos de usufruir de um tipo de vida que valoriza. Para se atingir esse tipo de vida, o indivíduo deve dispor de algumas liberdades instrumentais como: oportunidades econômicas, liberdades políticas, facilidades sociais, garantias de transparência e segurança protetora.

E a abordagem multidimensional entende que a pobreza consiste em um fenômeno social complexo, referente não apenas a privações em termos de necessidades materiais de bem-estar, mas também à negação de oportunidades de se levar uma vida dentro de padrões aceitáveis socialmente. Para essa abordagem, as múltiplas dimensões da vida humana devem ser levadas em conta na análise do nível de vida das pessoas. O não acesso a certos níveis de vida em determinadas dimensões configuraria uma situação de privação, podendo configurar-se ou não uma relação de pobreza, dependendo do método e das dimensões utilizadas para a análise (Barros; Carvalho; Franco, 2006; Kageyama; Hoffman, 2006; Serra, 2017).

Para o estudo em questão, optou-se por uma abordagem dos níveis de renda que definem a linha de pobreza, considerado como o dobro do valor da linha de extrema pobreza. Esta consiste em uma cesta de alimentos com o mínimo de calorias necessárias para suprir energeticamente uma pessoa de forma adequada, com base em recomendações da Organização para a Alimentação e Agricultura (FAO) e da Organização Mundial de Saúde (OMS), de acordo com o IPEADATA (2019). Ou seja, a linha de extrema pobreza é aquela que define o limite de reprodu- 
ção física das pessoas. Como a linha de pobreza é definida pelo dobro da linha de extrema pobreza, podemos considerar que a definição da primeira, aqui utilizada, permite a reprodução para além da reprodução física ou cotidiana.

Optou-se por essa definição porque em economias modernas e monetizadas (e urbanas), onde se consegue satisfazer as necessidades individuais através da renda, essa análise permite estabelecer seus níveis, que garantem o acesso do indivíduo às necessidades consideradas básicas e à sua reprodução dentro do ambiente onde vive. Essa opção também decorreu da maior facilidade de realização de análise de longo prazo sobre esse fenômeno, como queremos realizar neste trabalho, e da possibilidade de estabelecer comparações entre escalas espaciais distintas, como a comparação entre o comportamento da pobreza na metrópole do Rio de Janeiro e no total do Brasil.

A possibilidade da realização de análise de médio/longo prazo no Brasil sobre pobreza, decorre da utilização da Pesquisa Nacional sobre Amostra de Domicílios (PNAD), realizada anualmente pelo Instituto Brasileiro de Geografia e Estatística (IBGE), que possui dados para essa dimensão desde 1976 a 2015, ano em que essa pesquisa foi extinta.

\section{TRAJETÓRIA DA POBREZA NO} BRASIL E NA METRÓPOLE DO \% RIO DE JANEIRO década de 1970 girava em torno de 40\% (Gráfico 1), tendo se elevado para quase $50 \%$ em 1983 e 1984, o que significa dizer que, nesse último período, quase a metade da população
}

brasileira encontrava-se em situação de pobreza, correspondendo a um pouco mais de 60 milhões de pessoas. Porém, em pouco tempo, houve redução drástica do nível de pobreza no país, registrando-se no ano de 1986 um patamar de 26,4\%, mas voltando-se aos níveis dos anos iniciais do seu registro, já em 1987, quando a taxa foi de $38,7 \%$, e permaneceu acima de 40\% desse ano em diante até1993. A partir desse período, a taxa de pobreza se estabilizou em torno de $35 \%$ até o ano de 2003, momento em que a trajetória da pobreza passou a ser de contínua redução, salvo pequenas oscilações em contrário, até o ano de 2014, chegando ao patamar de 13,3\%, o menor nível já alcançado no país desde que se realiza seu registro, porém ainda representando um contingente de pouco mais de 25 milhões de pessoas. Em 2015, ano do último registro feito por meio da PNAD/IBGE, contudo, o nível da pobreza no país deu sinais de reversão.

De modo geral, a trajetória da pobreza existente na metrópole do Rio de Janeiro é semelhante ao que foi verificado no Brasil, nesse período de 1976 a 2014. No entanto, há diferenças de nível e de intensidade que merecem ser escrutinadas em cada uma das conjunturas históricas. Enquanto nos anos registrados na década de 1970 a pobreza no Brasil girava em torno de $40 \%$, ela só ultrapassou a taxa de $25 \%$ na metrópole do Rio de Janeiro no ano de 1979, quando já dava sinais de crescimento, o qual se verificou até o ano de 1984, momento em que atingiu o seu maior nível, registrando 40,1\%. Ou seja, a taxa de pobreza da metrópole do Rio de Janeiro apresentava nível inferior ao verificado no país, mas quando se observou seu crescimento na metrópole, foi de maior intensidade do que no conjunto do Brasil, pois, neste subiu de $40 \%$ para $50 \%$, enquanto naquela passou de menos de $25 \%$ para $40 \%$ - portanto, mais de 15 pontos percentuais de crescimento. Na metrópole, assim como no Brasil, também houve queda da taxa de pobreza nos anos de 1985 e 1986 e retorno do seu aumento no período subsequente, apesar de maiores oscilações até o ano de 
1993 quando registrou o nível de 39,2\%, muito próximo do verificado no país em seu conjunto. A partir de 1995, se estabilizou em torno de $25 \%$, ficando assim até 2002, quando nos dois anos seguintes passou a registrar nível superior a 30\%. De 2005 em diante, houve praticamente redução contínua do seu patamar, chegando ao final da série histórica registrando 17,5\%. De 2008 em diante, foi a primeira vez em toda sua trajetória que a taxa de pobreza da metrópole do Rio de Janeiro ultrapassou a do Brasil, ou registrou o mesmo patamar, apesar de também ter apresentado redução. Porém, do mesmo modo como observado no país, a taxa de pobreza na metrópole em 2015 voltou a se elevar, como se observa a seguir.

\section{MUDANÇAS ESTRUTURAIS OCORRIDAS NO BRASIL}

A passagem da década de 1970 para 1980 significou o encerramento de um longo período de crescimento econômico decorrente de políticas econômicas desenvolvimentistas, uma vez que os resultados econômicos e sociais já davam sinais de esgotamento desse processo caracterizado como de substituição de importações. Duas são as consequências mais emblemáticas do fim desse período de desenvolvimento: a elevada inflação e a dívida externa brasileira. A primeira, já se apresentava em patamares elevados desde a segunda metade da década de 1970, o que demonstra,

Gráfico 1 - Proporção de pessoas em situação de pobreza (em \%) - 1976 a 2015

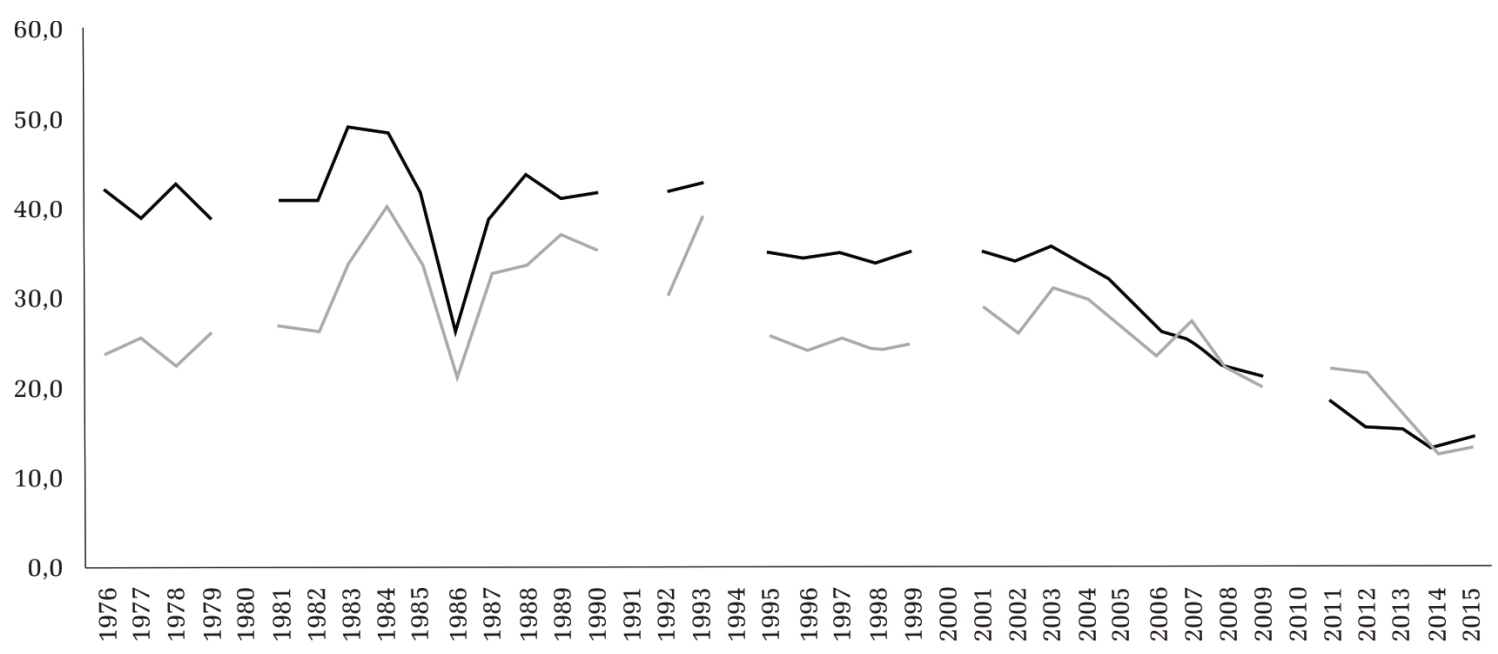

Fonte: PNAD/IBGE. Retirado do IPEADATA. RM RJ

A semelhança de trajetória entre as taxas de pobreza no Brasil e na metrópole do Rio de Janeiro nos diferentes períodos históricos analisados evidencia a necessidade de aprofundamento de cada conjuntura particular para o entendimento do seu comportamento. Ao mesmo tempo, as diferenças de níveis e de intensidade encontradas entre o Brasil e a metrópole do Rio de Janeiro, em cada uma das conjunturas destacadas, nos levam ao questionamento da particularidade da pobreza no contexto metropolitano vis-à-vis o país no seu conjunto. já nesse período, que a inflação estava atingindo níveis insuportáveis para a sociedade brasileira $^{2}$ (Abreu, 1990). Na entrada dos anos 1980, essa situação se agravou ainda mais, sendo contida em período muito reduzido, quando da implementação do Plano Cruzado, em 1986, que previa a estabilização monetária. Porém, de 1987 em diante, a inflação não só voltou a crescer, como assumiu níveis nunca

${ }^{2}$ O Deflator Implícito do PIB, que expressa a variação dos preços de toda a economia, era de 38,9\% em 1978, 55,8\% em 1979 e 91\% em 1980 (Abreu, 1990). 
registrados no país ${ }^{3}$ (Modiano, 1990), tornando-se um dos grandes problemas para a sociedade brasileira até meados de 1994, quando o Plano Real conseguiu estabilizar os preços na economia. Desse período em diante, os níveis da taxa de inflação passaram a ser reduzidos, ${ }^{4}$ sem nunca ter voltado aos patamares descontrolados, vivenciados em momento anterior, principalmente nos anos 1980. A segunda característica daquela passagem, a dívida externa brasileira, passou a ser um dos grandes problemas também a partir da década de 1980, decorrente do aumento da taxa de juros realizado pelo governo estadunidense e dos choques do petróleo ocorridos em 1973 e 1979. Como parte significativa do financiamento do desenvolvimento brasileiro se deu a partir de Investimento Estrangeiro Direto (IED), e pela contratação de empréstimos internacionais, no momento de aumento da taxa de juros pelos Estados Unidos, o endividamento brasi- leiro passou a ser incontrolável, ${ }^{5}$ o que levou a considerar-se, inclusive, a possibilidade de decretar moratória da dívida (Carneiro; Modiano, 1990). Apesar de não ter ocorrido, a dívida externa continuou a ser um dos grandes problemas brasileiros até o começo dos anos 2000, tornando-se um dos impedimentos de crescimento sustentável do país. Logo, tanto a inflação, como a dívida externa, passaram a ser consideradas como os principais problemas do país na década de 1980, e começo da década de 1990, tendo em vista suas consequências para a condição social da população brasileira, com um momento de grande redução do poder de compra, de estagnação dos níveis de renda, de aumento da informalidade, tudo isso se traduzindo em piora das condições de vida para população, conforme mostra o Gráfico 2.

A partir do início da década de 1990 a economia brasileira entrou em numa nova fase encerrando-se de vez a política de substituição

Gráfico 2 - Brasil: Renda domiciliar per capita, em R\$ de out. de 2014, taxa de desocupação e taxa de informalidade (em \%) - 1981-2015

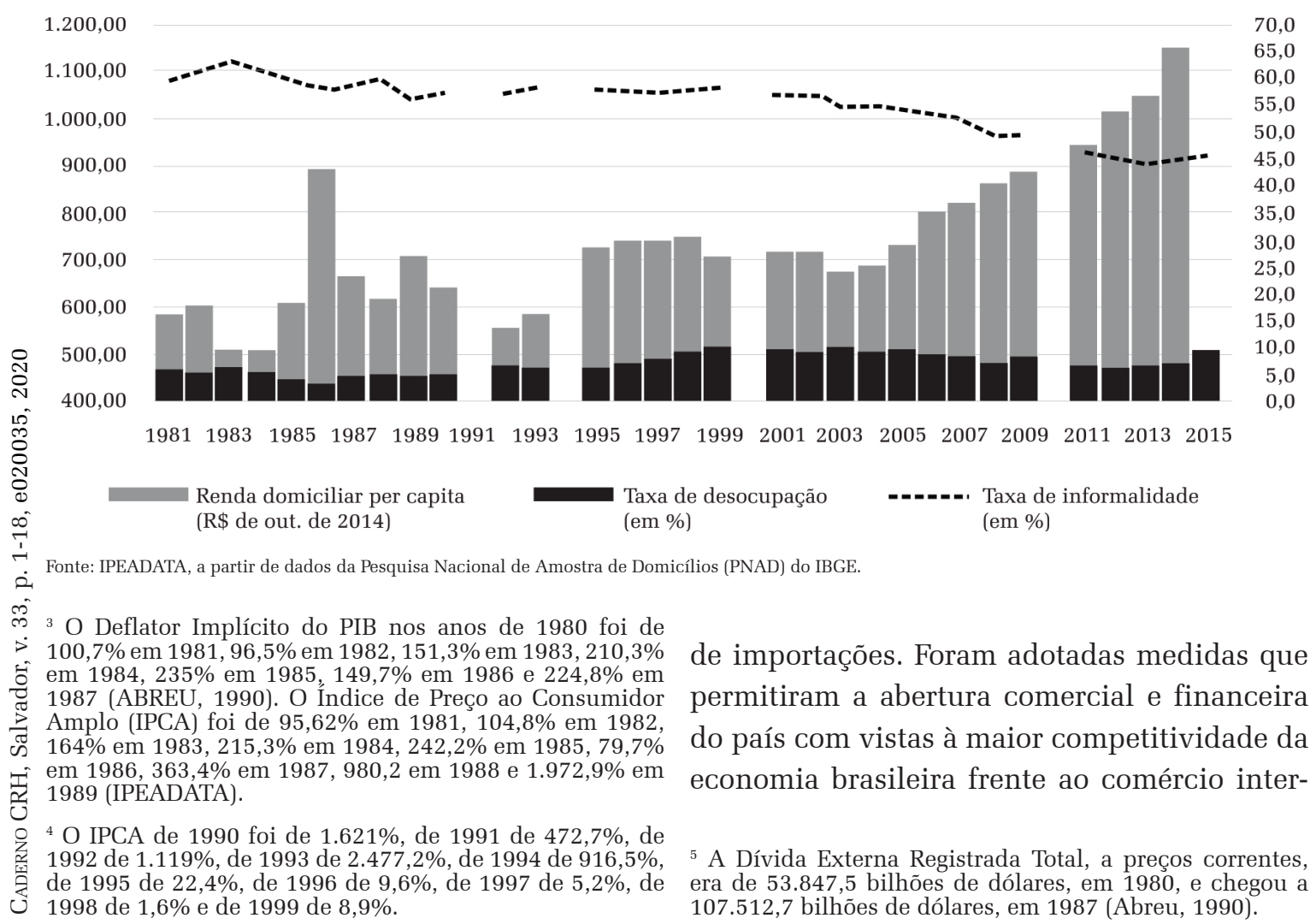


nacional e redução da participação do Estado na economia, fosse no seu processo regulatório, fosse na sua atuação como agente produtivo por meio do processo de desestatização. Essas medidas deflagradas ainda no começo da década de 1990 foram intensificadas a partir do Plano Real, em 1994, que buscou a estabilidade monetária. Apesar do sucesso desse principal objetivo do Plano Real, suas consequências sociais se deram, principalmente, pelo elevado nível de desemprego, aumento ainda maior da informalidade (Gráfico 2), precarização do trabalho, também em função de mudanças da estrutura produtiva industrial e de mudanças da estrutura do setor de serviços, que passou a ter maior proeminência desse período em diante, e elevada desigualdade de renda entre os grupos sociais (Oliveira; Turolla, 2003). Apesar do nível da pobreza ter sido menor do que no período anterior, sua taxa se estabilizou entre 1995 e 2003 em torno de 35\%, patamar ainda muito elevado na medida em que representa um grande contingente populacional do país. De todo modo, esse foi um período que demarcou a instalação de uma nova estrutura econômica no Brasil, presente até os dias atuais, conforme mostra o Gráfico 2.

Porém, de 2003 em diante, mesmo que inserido numa estrutura econômica que havia se instalado na década 1990, o país passou a elevar seu nível de crescimento econômico (Novelli, 2010), conforme mostra o Gráfico 3. Isso decorreu do aumento das exportações de commodities agrícolas e minerais em um cenário favorável do comércio internacional, mas também do aumento do consumo do mercado interno. Esse aumento do consumo do mercado interno foi induzido pela ampliação da renda dos grupos sociais de menor rendimento e, portanto, com maior propensão a consumir, mas também de investimentos públicos em infraestrutura, alavancando o setor da construção civil. Isto se deu em um contexto de aumento do nível de emprego, aumento da formalização do trabalho, elevação do salário (devido ao aumento real do salário-mínimo) e, por conseguinte, de redução das desigualdades de renda do trabalho (Gráfico 2). Nesse cenário, a população pôde ampliar sua capacidade de consumo e melhorar sua condição de vida a partir da obtenção de bens e serviços antes não alcançados (Barbosa; Souza, 2010), em um contexto no qual ocorreu a redução sistemática da taxa de pobreza no país. Isso, porém, não deve ser compreendido sem se levar em consideração as políticas sociais promovidas pelo governo federal, como foi o Programa Bolsa Família, tendo em vista que significou uma ampliação significativa da cobertura de transferência de renda em todo o país.

Gráfico 3: Brasil: PIB a preços básicos (em R\$ milhões de 2010) e variação real anual (\%) - 1995-2019

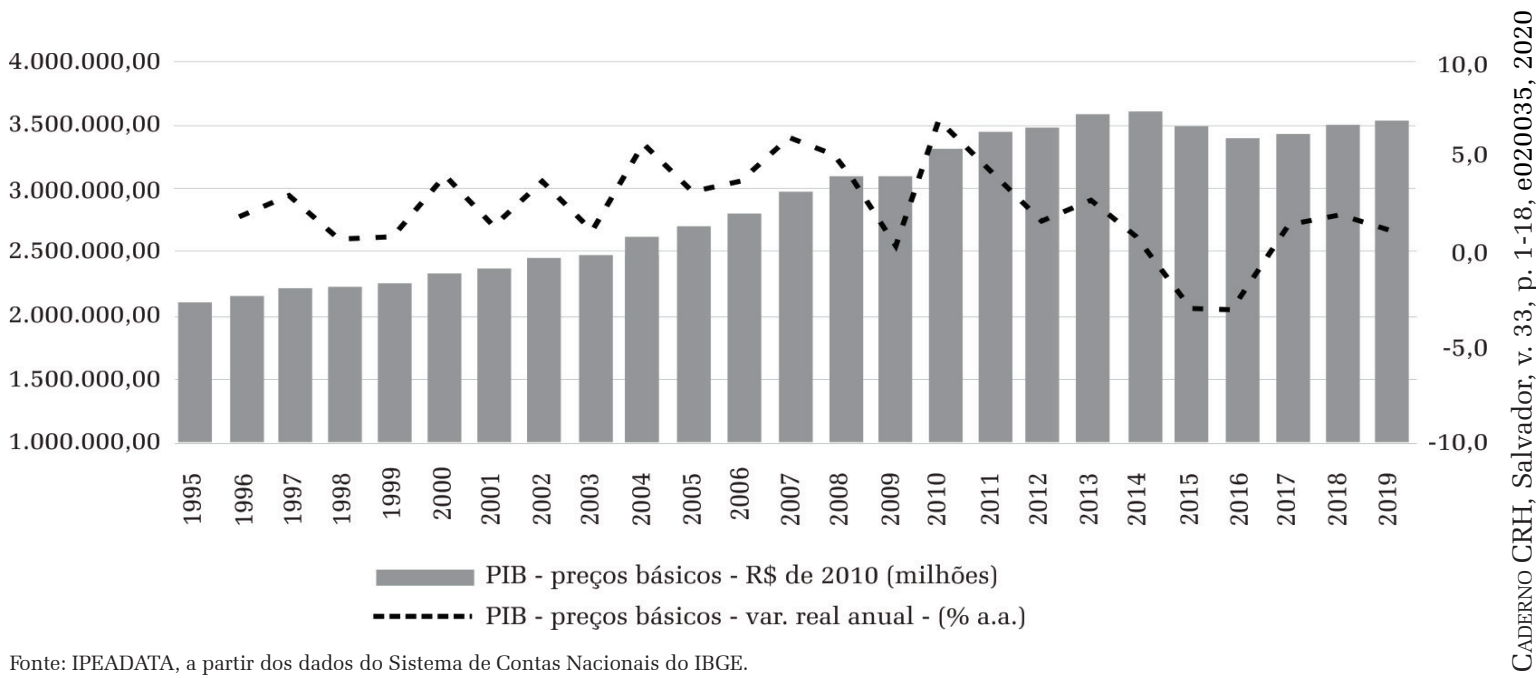


A partir de 2014 a economia brasileira começou a dar sinais de desaceleração, sofrendo os efeitos de mudanças do cenário internacional em decorrência da redução dos preços das commodities minerais, principalmente do petróleo, mas também dos efeitos da crise econômica que atingiram, num primeiro momento, os países desenvolvidos, como os Estados Unidos e vários países europeus e, posteriormente, os países em desenvolvimento, como foi o caso do Brasil. Isso se deu numa conjuntura de aumento do endividamento da população brasileira, o que contribuiu para a contração do consumo no mercado interno. Nesse contexto, ao invés de o Estado induzir o crescimento econômico, passou a adotar medidas fiscais contracionistas a partir do final de 2014, além de implementar uma política de elevação da taxa básica de juros da economia, ${ }^{6}$ colaborando ainda mais para a redução do seu crescimento. Nos dois anos seguintes, o Brasil apresentou crescimento econômico negativo, entrando de vez numa grave crise econômica que perdura até os dias atuais (2020). Uma das principais consequências sociais dessa situação foi o aumento do desemprego e a estagnação do aumento de renda do trabalho, freando a trajetória anterior e indicando a volta do aumento da taxa de pobreza em todo o país.

Essas diferentes conjunturas econômicas e sociais analisadas acima ajudam a entender a semelhança de trajetória entre as taxas จิ de pobreza do Brasil e da metrópole do Rio de - Janeiro. Apesar da semelhança, como vimos, há diferenças de níveis e de intensidade en\& tre as respectivas taxas de pobreza, o que nos $\stackrel{\infty}{\rightarrow}$ leva a buscar os elementos que caracterizam $\dot{\overrightarrow{2}}$ sua particularidade no contexto em que ela se ले apresenta.

${ }^{6}$ Desde meados de 2013 o Comitê de Política Monetária (COPOM) passou a elevar a taxa de juros Selic. Em março de 2013 a taxa de juros era de 7,25\%; em novembro de 2013 a taxa de juros passou para $10 \%$, em dezembro de 2014 , um ano depois, a taxa de juros foi registrada em $11,75 \%$, sendo elevada de modo contínuo até outubro de 2016.

\section{PARTICULARIDADES DA METRÓ- POLE DO RIO DE JANEIRO}

A metrópole do Rio de Janeiro apresenta algumas características estruturais muito particulares no espaço nacional. Destacamos aquelas características que possuem relação com a pobreza, como sua estrutura econômica e, por conseguinte, a estrutura do seu mercado de trabalho, suas dimensões demográfica e familiar, e sua condição urbana e metropolitana. No primeiro aspecto, a metrópole do Rio de Janeiro se caracteriza já há muito tempo pela prevalência das atividades de serviços, com destaque para os serviços relacionados ao turismo e à cultura, serviços de negócios e, também, os serviços referentes à administração pública. ${ }^{7}$ Os serviços relacionados ao turismo e à cultura que, em parte, se caracterizam como atividades formais, em parte também se caracterizam como atividades informais. Para compreendermos essa situação, a participação das pessoas empregadas sem carteira de trabalho assinada e por conta-própria, no total das ocupações de serviços na metrópole, era de $37,7 \%$ em 2015, de acordo com dados da Pesquisa Nacional por Amostra de Domicílios (PNAD) do IBGE; quando se considera apenas o subsetor de alojamento e alimentação, essa participação sobre para $48,3 \%$, o que expressa a magnitude da informalidade nas atividades vinculadas ao turismo.

Os serviços relacionados aos negócios decorrem do fato de a metrópole do Rio de Janeiro ser a segunda principal metrópole do país em termos econômicos e populacionais, o que possibilita que muitos escritórios de empresas nacionais e internacionais nela se localizem. Além disso, pelo fato de a cidade do Rio de Janeiro ter sido até o ano de 1960 a capital do país (e, hoje, ser a capital do atual Estado do Rio de Janeiro), há também concentração nes-

7 Em 2015, a participação do setor de serviços no Valor Adicionado Bruto (VAB) da metrópole do Rio de Janeiro foi de $61,4 \%$ e do setor de administração pública foi de $20,6 \%$. Os dois setores juntos corresponderam a $82 \%$ do total do VAB. Isso demonstra o peso das atividades de serviços em geral nessa metrópole. 
se território de muitos órgãos do setor público (tanto instituições federais quanto estaduais e municipais) como legado do seu passado como Distrito Federal.

O setor industrial tem menor participação na estrutura econômica da metrópole do Rio de Janeiro, ${ }^{8}$ mas apesar disso, ainda se apresenta como um dos principais centros industriais do país, mesmo com todo o histórico de redução de sua participação relativa na economia nacional. O tipo de atividade industrial presente na metrópole está ligada à indústria extrativista mineral, como é o caso da refinaria de petróleo presente em Duque de Caxias, mas também à indústria de transformação, apesar de serem indústrias de baixa e média-baixa intensidade tecnológica, em sua maioria. Com essa característica, podemos perceber como se estrutura seu mercado de trabalho, em que parte significativa de sua população ocupada se encontra no setor de serviços. ${ }^{9}$

Apesar de parte destas ocupações exigir alta qualificação, como são os casos dos serviços de negócios, da administração pública e, mesmo, de alguns segmentos dos serviços de turismo, há muitos serviços que exigem baixa qualificação e muitas dessas atividades são realizadas de modo informal, o que caracteriza os trabalhadores desse setor como aqueles que, em geral, possuem baixa remuneração e relações precárias de trabalho. Também pelo fato de prevalecer um tipo de indústria de baixa e média-baixa intensidade tecnológica, o tipo de mão de obra requerido em sua maioria é correspondentemente de baixa qualificação, mesmo tendo algumas empresas industriais de média-alta e alta intensidade tecnológica, mas que empregam proporcionalmente menos mão

${ }^{8}$ A participação do setor industrial no total do VAB da metrópole do Rio de Janeiro foi de 17,9\%, em 2015 (PIB Municipal, IBGE, 2015). Os vínculos de trabalho do setor industrial apresentavam participação de 10,8\%, em 2016, e a massa salarial referente a esses vínculos tinham participação de 13,6\% (RAIS, 2016).

${ }^{9}$ De acordo com a PNAD/IBGE de 2015, que compreende o trabalho formal e informal, as ocupações dos serviços correspondem a 67\%. Porém, de acordo com os dados da RAIS de 2016, que considera somente o trabalho formal, os vínculos de emprego do setor de serviços correspondem a $88,7 \%$. de obra, apesar de mais qualificada.

Quanto às características demográficas da sociedade da metrópole do Rio de Janeiro, sempre estiveram mais avançadas do que aquelas verificadas no conjunto do país, no sentido de que o Brasil apresenta tendência de chegar às condições que já são manifestadas nessa metrópole (Tavares; Oliveira, 2015). Um dos exemplos disso, diz respeito à esperança de vida ao nascer e à longevidade: ${ }^{10}$ isto é, o que já se coloca como realidade para o caso dessa metrópole é o fato de haver muitos idosos, mais proporcionalmente do que no conjunto do país. Esse comportamento da longevidade está associado, de alguma maneira, a mudanças na sua estrutura etária, haja vista uma redução do número de crianças/adolescentes e jovens, indicando um processo de aumento da população em ativa adulta e, mesmo, da população idosa. Algo que no país, ainda se demonstra grande, como é o número de pessoas jovens na estrutura etária (apesar de já haver indícios de redução no total de crianças/adolescentes), vê-se que a tendência nacional é chegar às condições já presentes na metrópole do Rio de Janeiro.

Esse tipo de comportamento tem a ver também com a redução da taxa de fecundidade, ${ }^{11} \mathrm{e}$, considerando que nesse momento histórico têm se reduzido as migrações inter-regionais na direção do Sudeste brasileiro, o crescimento populacional tem sido cada vez menor em termos relativos. Essas características demográficas estão associadas também a mudanças no tamanho e no padrão do arranjo familiar, tendo em vista que as famílias vêm reduzindo o número dos seus membros, deixando de ser famílias numerosas, como eram no passado, para ser famílias constituídas por

${ }^{10}$ Em 2010, a esperança de vida ao nascer da população brasileira era de 73,94 e para a população da Região Metropolitana do Rio de Janeiro de 76,01 anos, segundo dados do Censo Demográfico organizados pelo Atlas do Desenvolvimento Humano no Brasil (sd). A taxa de envelhecimento no Brasil era, no mesmo ano, de 7,36 e na RMRJ de 9,14.

11 A taxa de fecundidade para a Região Metropolitana do Rio de Janeiro caiu de 1,99 em 2000 para 1,66 em 2010 segundo dados do Censo Demográfico, organizados pelo Atlas do Desenvolvimento Humano no Brasil (sd). 
poucos integrantes. Além disso, o arranjo familiar tem deixado de se caracterizar, única e exclusivamente, pela composição de pai, mãe e filhos, passando a ter outras características, como mãe e filhos, pai e filhos, somente cônjuges etc. (Tavares; Oliveira, 2015).

Algo que pode passar despercebido mas que precisa ser melhor refletido é o fato de a metrópole do Rio de Janeiro ser eminentemente urbana, ${ }^{12}$ condição já alcançada desde os anos de 1960, quando se constituiu como realidade metropolitana no bojo do processo de urbanização brasileira e sendo institucionalmente reconhecida na década seguinte (Azevedo; Lobo, 2015). Apesar de o país ter apresentado altas taxas de crescimento urbano, ainda havia parcela significativa de sua população vivendo no meio rural. ${ }^{13} \mathrm{O}$ que se vê hoje é diferente do que havia se demonstrado nos anos 1960-70, pois menos de $15 \%$ da população do país reside no meio rural em 2020. Além disto, morar numa realidade urbana impõe limites coletivos para a reprodução cotidiana.

Em um contexto de crescimento econômico e de expansão do mercado de trabalho, como foram as décadas de 1950, 60 e 70, mesmo que não houvesse incorporação ao mercado de trabalho formal da economia, havia a possibilidade de se desenvolverem estratégias de sobrevivência, fazendo surgir trabalhos informais que garantissem, assim, a reprodução social nessa realidade urbana emergente. Poธิ rém, num contexto em que não há sinais de exน pansão econômica, tampouco de expansão do seu mercado de trabalho (ao contrário: com as mudanças estruturais ocorridas no país, modificou-se a estrutura de emprego com a redução da participação do setor industrial, ampliando

$>12$ Segundo dados da Pesquisa Nacional por Amostra de ث Domicílios (PNAD) de 2015, 99,8\% da população da Região Metropolitana do Rio de Janeiro residia em território urbano, enquanto que $0,2 \%$ em território rural.

${ }^{13}$ Segundo dados do Censo Demográfico, em 1991 a taxa de pessoas vivendo em situação rural no Brasil era de 24,4\% , enquanto que em 2010 essa taxa passou a ser de 15,63\% (IBGE, 2020). Segundo dados da Pesquisa Nacional por Amostra de Domicílios (PNAD) de 2015, 99,8\% da população da Região Metropolitana do Rio de Janeiro residia em território urbano, enquanto que $0,2 \%$ em território rural. e precarizando as atividades de serviços), as alternativas para a reprodução ficam limitadas.

Essas particularidades da metrópole do Rio de Janeiro vis-à-vis o conjunto do país nos levam a refletir sobre o sentido da pobreza atualmente, tendo em vista os sinais de retrocesso observados desde 2015. Em outras palavras, trata-se de velhos problemas que podem assumir contornos diferentes na atualidade, o que exige que se conheça, portanto, os novos dilemas colocados para que se possa almejar, e continuar almejando, a sua superação. No entanto, antes de realizar mais conclusivamente essa reflexão, convém observar as mudanças de algumas características das pessoas em situação de pobreza na metrópole do Rio de Janeiro.

\section{MUDANÇAS NO PERFIL DAS PES- SOAS EM SITUAÇÃO DE POBRE- ZA NA METRÓPOLE DO RIO DE JANEIRO}

O perfil das pessoas em situação de pobreza pode ter consequências diferentes a depender do contexto socioespacial onde estejam localizadas, haja vista que as alternativas de reprodução cotidiana se apresentam de modo diferente entre pequenas e grandes cidades e entre os espaços urbano e rural. Focar no perfil das pessoas em situação de pobreza na metrópole do Rio de Janeiro tem o caráter de refletir sobre sua possibilidade de reprodução nesse contexto sócio-espacial específico, uma vez que a condição de metrópole impõe constrangimentos e desafios que lhes são particulares para a reprodução social. Portanto, deixar de caracterizar o total do Brasil, nesta seção, decorre do fato de que há condições sócio-espaciais muito diferentes em âmbito nacional, o que requereria de nossa parte uma reflexão mais abrangente sobre os contextos existentes e as conseqüências resultantes de cada uma delas, algo que fugiria ao escopo deste trabalho. Em outras palavras, queremos dizer que 
o território da pobreza importa. Neste caso, vamos focar no território metropolitano, mais especificamente na particularidade da metrópole do Rio de Janeiro.

Para mostrar as mudanças no perfil das pessoas em situação de pobreza entre os anos de 1984 e 2014, escolhemos três variáveis que são características do perfil socioeconômico: estrutura etária, escolaridade e grupo ocupacional. É evidente que a impossibilidade de apresentação de outras variáveis importantes nessa caracterização decorreu da limitação dos dados utilizados. Porém, com as variáveis selecionadas, consideramos sermos capazes de indicar elementos importantes sobre seu perfil socioeconômico para reflexão e interpretação da pobreza na atualidade, considerando, todavia, que os anos escolhidos retratam momentos diferentes da situação da pobreza. $\mathrm{O}$ ano de 1984 foi aquele no qual ocorreu o maior nível da pobreza na metrópole do Rio de Janeiro desde ocorreram os registros sobre pobreza no país. O ano de 2014, ao contrário, foi aquele no qual ocorreu o menor nível de pobreza, ou seja, são os momentos mais adversos em termos do nível relativo de pobreza na metrópole do Rio de Janeiro. Mas as diferenças não são apenas relativas, pois, o número de pessoas em situação de pobreza em 1984 era de 3.375.456 pessoas, enquanto em 2014 o número de pobres foi de 1.566.617 pessoas. Ou seja, houve também redução absoluta no número de pessoas em situação de pobreza e essa redução foi de mais da metade no período considerado. Mesmo assim, este número ainda continua elevado e com tendência a ampliação, o que faz desse dado preocupante.

A primeira variável a ser observada diz respeito à estrutura etária e sua relação com o sexo e a faixa de idade dos indivíduos, como podemos observar no Gráfico 4. Trata-se de variáveis adscritas, mas essas características dos indivíduos sofrem as consequências do mundo social em que eles estão inseridos. Por isso, a análise de seu comportamento tem o caráter de refletir as condições de vida ou de repro- dução dos indivíduos. Como podemos observar, há diferenças entre a estrutura etária das pessoas em situação de pobreza entre os anos de 1984 e 2014. Do ponto de vista etário, no primeiro ano, a estrutura apresentava um perfil muito mais piramidal, tendo em vista que a base era mais alargada, sobretudo até a faixa de 10 a 14 anos, e sendo reduzida à medida que se aumenta as faixas de idade. A estrutura etária de 2014 tem deixado de apresentar um perfil piramidal na medida em que tem havido redução de sua base, mesmo que pequena, e aumentado a proporção de pessoas nas faixas intermediárias de idade, entre 20 a 44 anos, mas também nas faixas de maiores idade. Porém, isso tem ocorrido, principalmente, com as mulheres que, além de manterem uma base mais alargada, ao contrário dos homens, elevou sua proporção nas faixas intermediárias e mais velhas mencionadas. Curioso é observar que os homens não apresentam comportamento homogêneo; em algumas faixas, há aumento de sua proporção, embora outras faixas tenham apresentado redução.

Se fôssemos realizar a análise do ponto de vista das coortes etárias, considerando que se tratasse de uma mesma população (o que não corresponde exatamente aos fatos), poderíamos verificar, por exemplo, que as pessoas de 0 a 4 anos (que, em 1984, correspondiam a quase $14 \%$ dos indivíduos em situação de pobreza) estariam na coorte de 30 a 34 anos três décadas depois, correspondendo a pouco mais de 7\%, uma redução de quase a metade. Os motivos para essa redução podem ser vários, desde a saída da situação de pobreza, ao galgar melhores condições de vida, à queda da mortalidade, principalmente por se tratar uma população que vive em situação de vulnerabilidade social, inclusive do acesso à saúde. Apesar de ser um bom exercício para se pensar as mudanças na estrutura etária a partir de suas coortes, não podemos tirar conclusões consistentes quando estamos isolando na análise um grupo específico. De todo modo, esse exercício nos possibilita compreender que as 
condições das pessoas em situação de pobreza na atualidade são muito diferentes daquelas observadas em 1984. de 12 anos ou mais de instrução, passando de 0,3\% para 7,9\% no mesmo período. Ao considerar somente os últimos intervalos de ins-

Gráfico 4 - Estrutura etária das pessoas em situação de pobreza na metrópole do Rio de Janeiro - 1984 e 2014
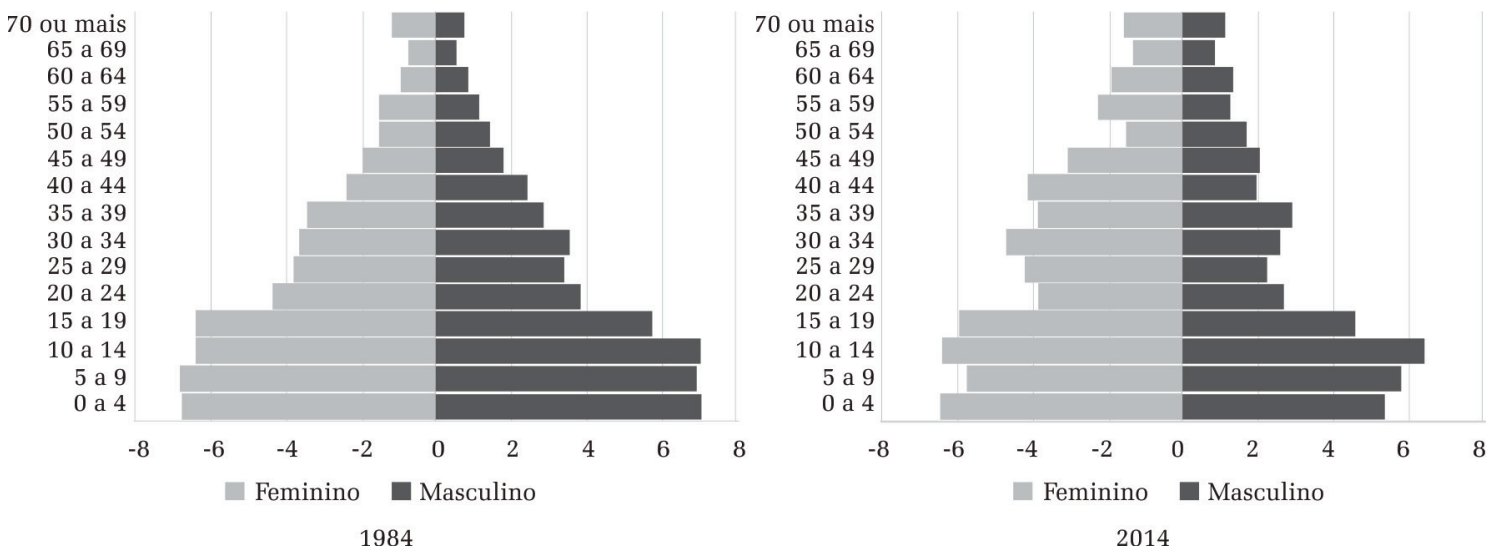

Fonte: PNAD/IBGE.

Adiante, o Gráfico 5 apresenta os dados de escolaridade das pessoas em situação de pobreza nos anos de 1984 e 2014. Podemos observar que não muda muito a proporção de pessoas sem instrução ou com menos de um ano de escolaridade, pois se reduz de $26 \%$ para $23,1 \%$. Porém, quando se observam os demais níveis de escolaridade, percebemos grandes diferenças entre os dois momentos. Em 1984, $69,1 \%$ das pessoas em situação de pobreza tinham de 1 a 8 anos de instrução, tendo reduzido para $46,2 \%$ em 2014. Ao mesmo tempo, houve aumento da proporção de pessoas entre 9 e 11 anos de instrução, passando de 4,6\%, 今ิ em 1984, para 22,8\%, em 2014, e de pessoas

Gráfico 5 - Nível de escolaridade das pessoas em situação de pobreza na metrópole do Rio de Janeiro (em \%) — 1984 e 2014

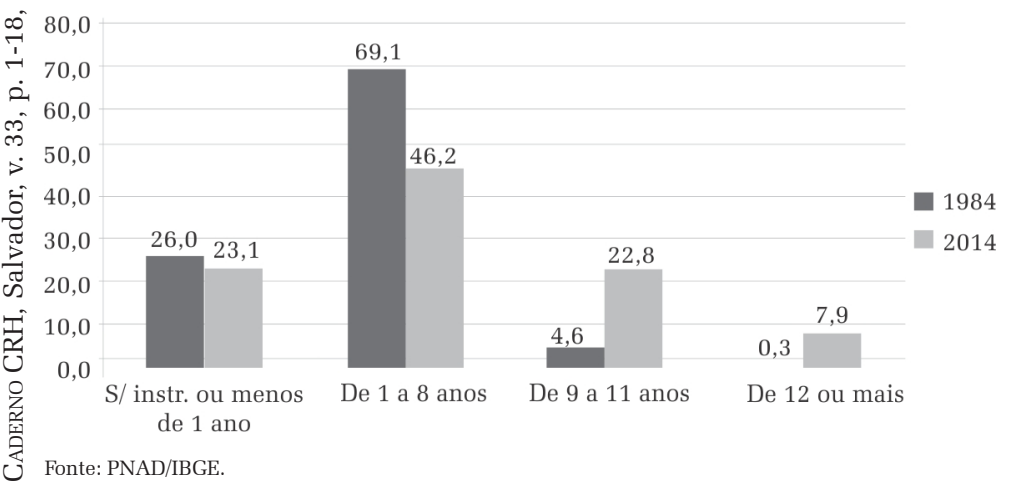

trução, podemos observar que a proporção de pessoas em situação de pobreza nessa condição passou de $4,9 \%$ para $30,7 \%$, o que significa que as pessoas estão mais escolarizadas e, portanto, com maiores condições de barganhar posições no mercado de trabalho em cargos que exijam maiores habilidades cognitivas. Ou seja, apesar de ainda haver muitas pessoas em situação de pobreza vivendo a condição de analfabetismo, na atualidade há também uma proporção muito grande de pessoas com nível de instrução elevado, tornando mais heterogêneo esse grupo social.

Para análise das ocupações que permitissem uma comparação entre 1984 e 2014, foi necessário realizar um traba-lho de compatibilização dessas ocupações por meio de grupos ocupacionais, como pode ser observado na Tabela 1. A dificuldade dessa tarefa decorreu do fato de a classificação ocupacional em 1984 ser diferente da classificação feita para 2014. Mesmo assim, chegamos a grandes grupos ocupacionais, o que permite uma avaliação de di- 
ferenças de posição no mercado de trabalho, principalmente entre as ocupações de trabalho manual e as ocupações de trabalho não manual. Assim, a análise do mercado de trabalho corrobora a análise do aumento da escolaridade, na medida em que também aumentou a proporção de pessoas em situação de pobreza em ocupações que requerem maior nível de instrução, como é o caso da categoria de "Profissionais das ciências e das artes; técnicos", que aumentou sua participação de 1,8\% para 12,1\%entre 1984 e 2014. Surpreende, todavia, que mesmo o número absoluto do total de pessoas ocupadas ter sido menor em 2014, também em razão da redução do número pessoas em situação de pobreza, houve aumento absoluto de pessoas nessa situação naquela categoria, passando de pouco mais de 21 mil pessoas para mais de 43 mil. As categorias "Trabalhadores administrativos" e "Prestadores de serviço" também aumentaram sua participação no período analisado, mas não apresentaram crescimento absoluto. Por outro lado, as categorias "Trabalhadores do comércio", "Trabalhadores da indústria" e "Trabalhadores agrícolas" demonstraram redução de sua participação, ao mesmo tempo que reduziram também em termos absolutos. Vale destacar que, em 1984, havia quase $18 \%$ de pessoas em ocupações mal definidas; essa proporção se reduziu em 2014 para $0,5 \%$, o que pode implicar no comportamento das categorias mencionadas acima.

De todo modo, o que se vê é que tem havido aumento de participação das pessoas em situação de pobreza nos trabalhos não manuais e redução da participação nos trabalhos manuais. Isso só pode ocorrer na medida em que essas pessoas passam a ter credenciais que permitem acesso a postos de trabalho que requerem maior nível de instrução, tendo em vista que são ocupações que exigem maiores habilidades cognitivas. Neste sentido, a análise do mercado de trabalho é compatível com a que vimos sobre a escolaridade, pois a sua ampliação para as pessoas em situação de pobreza tem possibilitado o acesso a postos de trabalho com maiores requerimentos de qualificação para ser exercido. Isso pode ser explicado, principalmente, pela condição dos jovens que estão em famílias em situação de pobreza, pois, apesar de terem conseguido melhorar seus atributos pessoais em termos de escolaridade e de posição no mercado de trabalho, por outro lado, não adquiriram rendimento suficiente para elevar o patamar de rendimento per capita da família, o que permitiria sua saída da situação de pobreza. Porém, num contexto de ampliação da escolaridade para toda a população em geral, que contribui para aumentar a oferta de trabalho de pessoas mais

Tabela 1 - Grupos ocupacionais das pessoas ocupadas em situação de pobreza na metrópole do Rio de Janeiro 1984 e 2014

\begin{tabular}{l|c|c|c}
\hline \multirow{2}{*}{ Grupos ocupacionais } & \multicolumn{2}{c}{1984} & \multicolumn{2}{c}{2014} \\
\cline { 2 - 4 } Profissionais das ciências e das artes; técnicos & N. & \multicolumn{2}{c}{ N. } \\
\hline Trabalhadores administrativos & 21.385 & 1,8 & 43.450 \\
\hline Prestadores de serviço & 57.924 & 4,8 & 29.173 \\
\hline Trabalhadores do comércio & 323.989 & 27,0 & 140.716 \\
\hline Trabalhadores da indústria & 141.140 & 11,8 & 33.065 \\
\hline Trabalhadores agrícolas & 354.364 & 29,5 & 95.972 \\
\hline Outras ocupações & 40.765 & 3,4 & 1.946 \\
\hline Ocupações mal definidas & 51.433 & 4,3 & 14.268 \\
\hline Total & 209.007 & 17,4 & 1.944 \\
\hline
\end{tabular}


escolarizadas, inflacionando as credenciais educacionais, isto leva à redução do nível de rendimento, mesmo de várias ocupações que requerem maior nível de escolaridade. Ou seja, quando os mais pobres passam a ter os atributos requeridos para ocupar posições mais elevadas no mercado de trabalho, se deparam com uma estrutura de emprego não compatível com toda a oferta de trabalho existente, o que impossibilita transformar posição social em recurso material (isto é, em rendimento).

Vimos, portanto, que as pessoas em situação de pobreza mudaram seu perfil entre a década de 1980 e de 2010. Agora, encontramos um grupo de pessoas mais jovens e também mais idosas, principalmente as mulheres, com maior nível de instrução, apesar de ainda haver elevado nível de pessoas analfabetas, e que têm exercido ocupações características do trabalho não manual, onde se requer maiores habilidades cognitivas para seu exercício. Diante da constatação dessa mudança de perfil e do que analisamos antes sobre o Brasil e a metrópole do Rio de Janeiro, importa refletir sobre o sentido da pobreza na atualidade.

\section{O SENTIDO DA POBREZA NA QUADRA ATUAL}

Após um período de mais de dez anos registrando redução do nível de pobreza (enชิ tre meados dos anos 2000 e meados dos anos i 2010), o retorno do seu crescimento suscita \&̊ questionamentos que vão além dos seus mo\& tivos causadores. Requer que compreendamos $\rightarrow$ que, nesse período, ou numa visão de mais $\dot{\sim}$ longo prazo, houve mudanças importantes que ले ocorreram no país e que precisam ser conside-

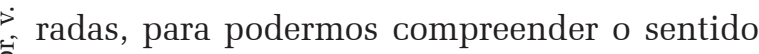
da pobreza na quadra atual. Isso é relevante porque o modo como é percebido o fenômeI no social também influencia no modo como se dá o tratamento das medidas elaboradas para seu enfrentamento. Apesar de viver em situação de pobreza, esta parte da população na atualidade é diferente da população pobre em décadas anteriores, o que está relacionado ao próprio movimento de mudanças ocorridas em toda a sociedade. Portanto, refletir sobre o sentido da pobreza na quadra atual requer que sua compreensão esteja inserida no marco das mudanças estruturais do país. São mudanças de ordem econômica, do mercado de trabalho, demográfica e familiar, mas também são mudanças em termos de expectativas sociais.

Como a estrutura econômica do Brasil é hoje, mais do que no passado, assentada no setor de serviços, e num contexto em que a sociedade é em sua maioria urbana, a possibilidade de os pobres poderem superar essa condição por meio de inserção no mercado de trabalho fica limitada. As alternativas de realização de trabalhos informais e precarizados e que exigem menor qualificação continuam sendo viáveis, mas a inserção de maior parcela da população na realização desse tipo de atividade econômica implica maior competição entre aqueles que nela estão inseridos. Se a economia não se mostrar dinâmica (e cujo dinamismo normalmente ocorre impulsionado pelo setor industrial, principalmente), o setor de serviços não será capaz de sustentar o crescimento econômico, tampouco as melhores condições de inserção social. Em meio à maior competição nos ramos de serviços que se caracterizam por condições precárias de trabalho, ao invés de melhoria das condições de vida da população em situação de pobreza que passam a se inserir nesses ramos, poderá haver redução generalizada dessas condições de vida para os pobres e para a população que já estava inserida nesses ramos econômicos.

As mudanças demográficas e familiares também podem significar maiores constrangimentos para a possibilidade de superação da pobreza. Do ponto de vista demográfico, como vimos, o aumento da longevidade acompanhado de mudanças na estrutura etária tem reduzido a proporção de crianças/adolescentes e aumentado a proporção de jovens e adultos. Num mercado de trabalho em que há menor 
demanda por trabalho em relação à sua oferta, como é a situação atual marcada pelo aumento do desemprego, a preferência por mão de obra tende a ser para os segmentos sociais mais vulneráveis socialmente, que se sujeitam com maior facilidade às condições de trabalho impostas, especialmente, depois de ter sido aprovada legalmente a flexibilização nas relações contratuais de trabalho. Do ponto de vista das mudanças familiares, especialmente pelas mudanças do seu tamanho e de seus arranjos, requer mudanças nas suas estratégias para que possam obter recursos (rendimentos) capazes de serem socializados por todos os seus membros. Como as famílias hoje são menores do que no passado, há menos alternativas para inserção no mercado de trabalho de seus membros. Além disso, nas famílias cujo responsável é sem cônjuge, também há maior proporção de pessoas em condições de pobreza em relação às famílias com a existência de casal (IBGE, 2018). Isso pode decorrer do fato de que famílias formadas por casal, têm maiores condições de compartilhamento dos recursos obtidos na medida em que também há uma dupla possibilidade de obtê-los, por cada um dos cônjuges ou pelo casal (ou, ainda, pelos filhos). Isso difere de famílias cujo responsável é sem cônjuge, pois a possibilidade de obtenção de recursos fica mais limitada a um único membro, ou aos seus outros membros, como os filhos.

Outro fato que não pode ser negligenciado é que a maior parte das pessoas em situação de pobreza é do sexo feminino. Numa sociedade que se caracteriza pela desigualdade sexual, observada em várias dimensões da vida, inclusive no mercado de trabalho, isso demonstra a dificuldade de as mulheres se inserirem de modo estável e com níveis de remuneração compatíveis com os requerimentos das ocupações em que realiza seu exercício. Neste caso, as mulheres em situação de pobreza que adquiriram as credenciais necessárias para exercer ocupações que requerem maiores habilidades cognitivas sofrem duplamente a discriminação no mercado de trabalho: sofrem por serem mu- lheres e sofrem por serem pobres. Associado a todos esses aspectos destacados, o retorno da pobreza após um longo período de melhoria da distribuição de renda do trabalho, aumento real do salário-mínimo, da formalização do trabalho e da capacidade de consumo (que, em conjunto, melhoraram as condições sociais da população de modo geral) pode frustrar as expectativas dos segmentos que se encontram na situação de pobreza, ou mesmo daqueles que estão na iminência de entrar nessa situação devido a outro aspecto fundamental para nossa reflexão: houve aumento do nível de escolaridade da população brasileira. Esse fato é relevante de se considerar porque há, na literatura especializada, a explicação da baixa escolaridade dos indivíduos como justificativa para a não inserção de pessoas no mercado de trabalho, ou para sua inserção de modo precário. Essa seria a principal explicação das baixas remunerações e, portanto, das diferenças de rendimento entre os indivíduos. Contudo, à medida que a escolaridade aumenta para a população em geral, o que se vê são pessoas com elevados níveis de instrução, mas que não se encontram inseridas no mercado de trabalho, ou inseridas de modo precário. O que se vê, portanto, é que, mesmo nas famílias em situação de pobreza, houve aumento da escolaridade, o que põe em questionamento o pressuposto de que a obtenção de maior escolaridade seria determinante para as pessoas obterem maiores rendimentos e, por conseguinte, saírem dessa situação.

\section{CONSIDERAÇÕES FINAIS}

Objetivamos, neste trabalho, analisar e discutir a trajetória da taxa de pobreza no Brasil e na metrópole do Rio de Janeiro, no período de 1976 a 2015, cuja escolha correspondendo a quatro décadas, foi feita para termos uma compreensão mais ampla da situação de pobreza, tanto no país quanto na metrópole em questão, de modo a identificar as permanências e mudanças deste fenômeno na atualidade. Além 
disso, a análise do contexto da metrópole do Rio de Janeiro vis-à-vis o contexto nacional também possibilitou identificar as particularidades desse fenômeno numa realidade metropolitana. Neste sentido, as primeiras constatações feitas são de que a trajetória da taxa de pobreza na metrópole e a trajetória no país foram semelhantes ao longo dessas quatro décadas, de modo que o seu comportamento está associado à conjuntura econômica e, por conseguinte, à conjuntura do mercado de trabalho. Porém, houve diferenças de níveis e de intensidade da taxa de pobreza entre a metrópole e o país, tendo em vista que as particularidades do contexto metropolitano fazem com que a manifestação da pobreza seja diferente entre esses diferentes contextos espaciais. Por esse motivo, buscamos refletir sobre a estrutura econômica, a estrutura do mercado de trabalho, os aspectos demográficos e familiares, além da dimensão urbanometropolitana que dão contornos particulares para a metrópole do Rio de Janeiro em relação à análise do fenômeno da pobreza feita em nível nacional.

A partir da compreensão do que é geral e do que é particular sobre o fenômeno da pobreza na metrópole do Rio de Janeiro, procuramos analisar as mudanças do perfil das pessoas em situação de pobreza nesse contexto metropolitano, comparando as variáveis de estrutura etária, escolaridade e grupo ocupacional entre os anos de 1984 e 2014, uma vez que esses foసิ ram os anos em que foram registrados a maior N e a menor taxa de pobreza, respectivamente, na metrópole do Rio de Janeiro. A análise de mudanças de perfil das pessoas em situação de $\rightarrow$ pobreza forneceu subsídios para realização da ¿. reflexão sobre o sentido da pobreza na atualiळ dade. Assim, pudemos observar que, hoje, as

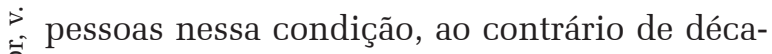
das atrás, estão mais jovens/adultas, possuem níveis de instrução mais elevados e chegam a exercer ocupações que representam posições sociais mais elevadas na estrutura social. Essa constatação nos leva à consideração de que, dado o retorno do aumento da pobreza nos últimos anos, a situação da pobreza na atualidade é enfrentada com muito mais frustração do que no passado, o que se deve ao fato de parcela importante das pessoas que se encontram nesta situação apresentarem os requisitos e credenciais necessários para não estarem em tal situação, apesar de estarem. Na medida em que não conseguem encontrar alternativa para superar esse quadro em que se encontram, as frustrações individuais (e também coletivas) tendem a se apresentar com mais intensidade, o que colabora para redução de expectativas de superação dessa realidade.

Como pudemos observar, o modo como o fenômeno da pobreza se manifesta no contexto metropolitano é diferente quando analisado no país um todo. Porém, a análise do contexto metropolitano em conjunto pode camuflar, ao invés de revelar, as diferenças existentes dentro da metrópole. Isso porque as desigualdades sociais e as desigualdades urbanas são características observáveis entre os diferentes espaços existentes dentro da metrópole, em especial da metrópole do Rio de Janeiro. É evidente que os dados utilizados para analisar a pobreza não permitem desagregação na escala intrametropolitana, motivo pelo qual a análise se restringiu ao conjunto da metrópole. Porém, se mesmo numa análise em conjunto podemos observar as particularidades metropolitanas no fenômeno da pobreza, coloca-se como questionamento a sua manifestação em contextos específicos do espaço metropolitano, considerando a estrutura desigual de organização social da metrópole do Rio de Janeiro (Ribeiro; Ribeiro, 2015).

Recebido para publicação em 11 de julho de 2019 Aceito em 07 de dezembro de 2020

\section{REFERÊNCIAS}

ABREU, M. P. "Anexo Estatístico". In: ABREU, M. de P. (org.). A ordem do progresso: cem anos de política econômica republicana, 1889-1989. Rio de Janeiro: Campus, 1990, p. 388-412. 
ATLAS DO DESENVOLVIMENTO HUMANO NO BRASIL. Website oficial [s.d.]. Disponível em: http://www. atlasbrasil.org.br/consulta. Acesso em 13 nov. 2020.

AZEVEDO, S.; LOBO, Y. "O processo de fusão e o novo Estado do Rio de Janeiro: a questão institucional”. In: RIBEIRO, L. C. Q. Rio de Janeiro: transformações na ordem urbana. Rio de Janeiro: Letra Capital; Observatório das Metrópoles, 2015, pp. 45-78.

BAGOLIN, I. P.; ÁVILA, R. P. POVERTY DISTRIBUTION AMONG THE BRAZILIAN STATES: A MULTIDIMENSIONAL ANALYSIS USING CAPABILITIES AND NEEDS APPROACHES. In: ENCONTRO NACIONAL DE ECONOMIA, XXXIV., 2006, Salvador. Anais... Salvador: ANPEC, 2006, v. 1, pp. 39-50.

BARBOSA, N.; SOUZA, J. A. P. de. "A Inflexão do Governo Lula: Política Econômica, Crescimento e Distribuição de Renda”. In: SADER, E.; GARCIA, M. A. (Org.). Brasil: entre o Passado e o Futuro. São Paulo: Boitempo, 2010, p. 1-42.

BARROS, R. P.; CARVALHO, M.; FRANCO, S. Pobreza multidimensional no Brasil. Rio de Janeiro: Ipea, 2006 (Texto para discussão, n. 1227).

BOURDIEU, P. O poder simbólico. $6^{\mathrm{a}}$ ed. Rio de Janeiro; Bertrand Brasil, 2003.

CARNEIRO, D. D.; MODIANO, E. "Ajuste externo e desequilíbrio interno: 1980-1984”. In: ABREU, M. P. (org.). A ordem do progresso: cem anos de política econômica republicana, 1889-1989. Rio de Janeiro: Campus, 1990, p. 323-346.

CODES, A. L. M de. A trajetória do pensamento científico sobre pobreza: em direção a uma visão complexa. Brasília: IPEA, abril de 2008 (TD 1332).

INSTITUTO BRASILEIRO DE GEOGRAFIA E ESTATÍSTICA (IBGE). Pesquisa Nacional por Amostra de Domicílio (PNAD), 1976-2015. Disponível em: http://www. ibge.gov.br. Acesso em: 01/11/2018.

Síntese de indicadores sociais: uma análise das condiçốes de vida da população brasileira: 2018 / IBGE, Coordenação de População e Indicadores Sociais. - Rio de Janeiro : IBGE, 2018.

Sistema IBGE de Recuperação Automática (SIDRA), 2020. Censo Demográfico - Séries Temporais. Disponível em: https://sidra.ibge.gov.br/pesquisa/censodemografico/series-temporais/series-temporais. Acesso em 13.11. 2020
Sistema IBGE de Recuperação Automática (SIDRA), 2020.Pesquisa Nacional de Domicílios - PNAD. Disponível em: https://sidra.ibge.gov.br/pesquisa/pnad/ geral/pesquisa-basica. Acesso em 13.11. 2020.

IPEADATA. Pobreza - número de pessoas pobres [s.d.] Disponível em http://www.ipeadata.gov.br. Acesso em 06/05/2019.

KAGEYAMA, A.; HOFFMANN, R. Pobreza no Brasil: uma perspectiva multidimensional. Economia e Sociedade, Campinas, v. 15, n. 1 (26), pp. 79-112, jan./jun. 2006.

MINISTÉRIO DA ECONOMIA - Relação Anual de Informações Sociais (RAIS), Brasília, DF - 2016. Disponível em: https://www.gov.br/economia/pt-br. Acesso em: $01 / 11 / 2018$

MODIANO, E. "A ópera dos Três Cruzados: 1985-1989". In: ABREU, M. P. (org.). A ordem do progresso: cem anos de política econômica republicana, 1889-1989. Rio de Janeiro: Campus, 1990, pp. 347-387.

NOVELLI, J. M. N. A questão da continuidade da política macroeconômica entre o governo Cardoso e Lula (19952006). Rev. Sociol. Polít. Curitiba, v. 18, n. 36, pp. 227-240, jun. 2010 .

OLIVEIRA, G.; TUROLLA, F. Política econômica do segundo governo FHC: mudança em condições adversas. Tempo Social, São Paulo, v. 15., n. 2, pp. 195-217, nov. 2003.

RIBEIRO, L. C. Q.; RIBEIRO, M. G. "Segregação residencial: padrões e evolução". In: RIBEIRO, L. C. Q. (org). Rio de Janeiro: transformações na ordem urbana. Rio de Janeiro: Letra Capital; Observatório das Metrópoles, 2015, pp. 163192.

ROCHA, S. Pobreza no Brasil: afinal, de que se trata? Rio de Janeiro: Ed. FGV, 2003.

SERRA, A. S. Pobreza Multidimensional no Brasil rural e urbano. 2017. Tese (Doutorado em Desenvolvimento Econômico) - Instituto de Economia, Universidade Estadual de Campinas, Campinas (SP).

TAVARES, É.; OLIVEIRA, R. A. D. "A metrópole fluminense na transição demográfica e urbana brasileira”. In: RIBEIRO,

L. C. Q. Rio de Janeiro: transformações na ordem urbana. Rio de Janeiro: Letra Capital; Observatório das Metrópoles, 2015, pp. 117-147. 


\section{POVERTY IN BRAZIL AND THE RIO DE JANEIRO METROPOLIS: old problems, new dilemmas}

\author{
Marcelo Gomes Ribeiro \\ Felipe Camargo Raitano
}

We aim to analyze the trajectory of poverty in Brazil and the metropolis of Rio de Janeiro, from 1976 to 2015, considering the structural changes in the Brazilian economy and society and the metropolitan context's particularities. The poverty line used was defined by double the level of income sufficient for the acquisition of food necessary to guarantee the individual's social reproduction. We could observe that the poverty rate varied according to the economic situation, with differences in levels and intensity between the metropolis and the country. Currently, unlike decades ago, people living in poverty are generally younger, have higher levels of education, and work in occupations that represent more prominent social positions in the social structure, which may have important implications in the changes in expectations of overcoming this condition, especially in the metropolitan context.

KeYwords: Poverty. Metropolis of Rio de Janeiro. Brazil. Economic Development. Economic Structure.

\section{LA PAUVRETÉ AU BRÉSIL ET LA MÉTROPOLE DE RIO DE JANEIRO: vieux problèmes, nouveaux dilemmes}

\author{
Marcelo Gomes Ribeiro \\ Felipe Camargo Raitano
}

Notre objectif est d'analyser la trajectoire de la pauvreté au Brésil et dans La métropole de Rio de Janeiro, de 1976 à 2015, enprenanten compte lês changements structurels de l'économie et de La société brésilienne ainsi que dês particularités Du contexte métropolitain. Le seuil de pauvreté utilisé a été defini comme celui correspondant le double du niveau de revenu suffisant pour l'acquisition d'um panier alimentaire de base, nécessaire pour garantir la reproduction cotidiene de l'individu. Nous avons pu constater que le taux de pauvreté variait en fonction de la conjoncture économique, avec des différences de niveaux et d'intensité entre la métropole et le pays. À la différence des décennies précédentes, les personnes vivant aujourd'hui dans la pauvreté sont généralement plus jeunes, ont un niveau de formation plus élevé et occupent des professions qui représentent des positions sociales plus importantes dans la structure sociale, ce qui peut avoir des conséquences importantes dans la façon de surmonter cette condition, en particulier dans le contexte métropolitain.

Motsclés:Pauvreté. Métropole de Rio de Janeiro. Brésil. Développementéconomique. Structureéconomique. metropolitana. 